\title{
Parametric analysis of the elastohydrodynamic lubrication efficiency on induced seismicity
}

\author{
Chiara Cornelio $^{\circledR}$ and Marie Violay ${ }^{\odot}$ \\ Laboratory of Experimental Rock Mechanics EPFL, CH-1015 Lausanne, Switzerland.E-mail: chiara.cornelio@epfl.ch
}

Accepted 2020 April 16. Received 2020 April 15; in original form 2020 January 22

\begin{abstract}
SUMMAR Y
During reservoir stimulations, the injection of fluids with variable viscosities can trigger seismicity. Several fault lubrication mechanisms have been invoked to explain the dynamic stress drop occurring during those seismic events. Here, we perform a parametric analysis of the elastohydrodynamic fault lubrication mechanism to assess its efficiency during fluidinduced earthquakes. The efficiency of the mechanism is measured with the dimensionless Sommerfeld number $S$. Accordingly, we analysed eight well-documented cases of induced seismicity associated with the injection of fluids whose viscosities range from $1 \mathrm{mPa} \mathrm{s}$ (water) to $100 \mathrm{mPa}$ s (proppant). We collected information related to the in situ stress field, fault orientation and geometry, moment of magnitude and static stress drop of the events. These parameters allow us to analyse the variation in the Sommerfeld number. Our results show that the estimated dynamic friction on the fault during the event is compatible with the fault weakening predicted by the elastohydrodynamic lubrication theory, particularly for highly viscous fluids.
\end{abstract}

Key words: Earthquake dynamics; Induced seismicity; Dynamics and mechanics of faulting; Fractures, faults, and high strain deformation zones.

\section{INTRODUCTION}

In the last $30 \mathrm{yr}$, the increase in man-induced earthquakes associated with wastewater disposal, gas storage or geothermal exploitation (Ellsworth 2013; Zoback \& Kohli 2019) has become an important scientific and social issue (Suckale 2009; Grigoli et al. 2017). The seismicity induced by fluid injection was first shown by Evans (1966) and Healy et al. (1968) for the earthquakes occurring after the beginning of injection of waste fluids near to Denver, Colorado. Later, Raleigh et al. (1976) conducted the first water injection field experiment at high pressure in the Rangely Oil Field, Colorado. It has also been demonstrated that the volume and rate of fluid injection (McGarr et al. 2014; Weingarten et al. 2015) control the fluid pressure increase (Hsieh \& Bredehoeft 1981) and determine the number and magnitude of the events.

However, fluid overpressure is not the only parameter governing fault reactivation and the associated seismicity (Noël et al. 2019). Recent studies have demonstrated that the thermal properties of fluids (i.e. compressibility, latent heat and thermal diffusivity) and physical properties (i.e. density and viscosity) can influence the rock-fluid interactions (Acosta et al. 2018) and, in general, the fault strength. In particular, Cornelio et al. $(2019,2020)$ have recently shown that high fluid viscosity might also play a role in decreasing the dynamic fault strength and, consequently, promoting the propagation of earthquakes. They experimentally showed that the onset of reactivation is independent of the on-fault fluid viscosity (i.e. the static friction coefficient is not a function of the viscosity) and the possible activation of the elastohydrodynamic (EHD) lubrication mechanism on the fault during seismic slip. Within the EHD theory, the state of the sliding surfaces can be distinguished in three different lubrication regimes as a function of the dimensionless Sommerfeld number $S$, defined as $S=6 \eta V L /\left(P_{\text {eff }} H^{2}\right)$, where $\eta$ is the fluid viscosity at the mean estimated surface temperature under steady state, $V$ is the slip rate, $P_{\text {eff }}$ is the effective normal stress, $L$ is the characteristic slip length and $H$ is the initial average asperity height (Fig. 1). In particular, for almost planar surfaces with asperities that are intermediately in contact during coseismic sliding, the average asperity height $H$ is of the same order of the average fluid film thickness (Brodsky \& Kanamori 2001).

(i) Faults under a boundary lubrication (BL) regime occur when $S<10^{-3}$ and the normal stress is supported by the solid-solid contacts and when the dynamic friction coefficient is close to static friction coefficient; (ii) faults under a fully lubricated regime (EHD) occur when $S>1$ and the normal stress is supported by the interstitial fluid; (iii) faults under a mixed lubrication (ML) regime occur when $10^{-3}<S<1$ and the normal stress is supported by both partially by the solid-solid contacts and partially by the interstitial fluid (criteria of lubrication regimes are derived from experimental studies, see Cornelio et al. 2019). In both the cases (ii) and (iii), the dynamic friction coefficient is strongly reduced compared to the static friction coefficient. Cornelio et al. (2019) also showed that the EHD mechanism is independent of the rock lithology. 


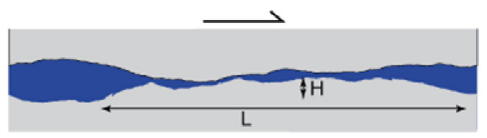

Boundary Lubrication

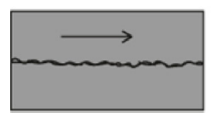

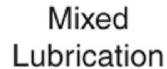

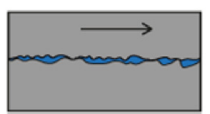

Hydrodynamic Lubrication

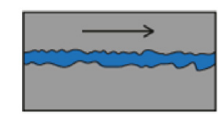

Figure 1. Schematic representation of the asperity contacts in the three different regimes. In the boundary lubrication regime, the load is supported by the asperity, and the fluid has no influence on the slip propagation. In the mixed lubrication regime, the load is partially supported by the asperity and partially supported by the film fluid present between the two sliding surfaces. In hydrodynamic lubrication, all the stress is supported by the fluid film, which completely controls the behaviour of the slipping surface.

Here, we analyse the possible ranges of the five parameters $\left(\eta, V, L, P_{\text {eff }}\right.$, and $H^{2}$ ) that define the Sommerfeld number $S$ for natural earthquakes, and we compare them with the estimated values of the same five parameters for eight cases of induced seismicity associated with the injection of different viscous fluids (water, brine, wastewater and proppant). We aimed to understand whether the EHD can be an efficient lubrication mechanism involved in induced earthquakes propagation.

\section{S PARAMETERS FOR INDUCED SEIS MICITY}

We will now discuss the possible range in values of the five parameters $\left(\eta, V, L, P_{\text {eff }}\right.$ and $H^{2}$ ), which define the $S$ number for natural earthquakes. In particular, we will determine the minimum and maximum values of (i) the fault geometrical parameters $\left(L / H^{2}\right)$, (ii) the fluid viscosity $(\eta)$, (iii) the effective normal stress $\left(P_{\text {eff }}\right)$ and (iv) the coseismic slip rate $(V)$ during earthquake propagation.

(1) $L / H^{2}: H(\mathrm{~m})$ is the average fault asperity height and $L(\mathrm{~m})$ is the characteristic dimension of pressure change, that is, the length over which the pressure of the film changes significantly compared to the average pressure on the fault interface. $L$ is proportional to the wavelength of the surface roughness (Brodsky \& Kanamori 2001). The most favourable scenario for the activation of EHD lubrication (maximum value for $S$ ) results from the largest possible $L$, that is, maximum wavelength of the surface roughness that correspond to the finite slip of the event (Brodsky \& Kanamori 2001). Moreover, the roughness of naturally exposed faults follows a power-law function of wavelength $H=B L^{\zeta}$, with $B$ being a constant prefactor ranging between $10^{-3}$ and 0.1 for naturally exposed faults (Brodsky et al. 2011). Surfaces described by the power-law scaling with $\zeta=1$ are defined as self-similar, while those with $\zeta \neq 1$ are known as being self-affine. $\zeta$ of the natural fault is between 0.6 and 1 (Brodsky et al. 2016 and references herein). Therefore, the $H / L$ ratio for natural faults ranges between 0.001 and 0.01 . Considering that earthquake slip can vary from a few millimetres $(L \sim 0.001 \mathrm{~m})$ to several metres $(L \sim 10 \mathrm{~m}), L / H^{2}$ ranges from $\sim 10^{3} \mathrm{~m} \mathrm{~m}^{-2}$ to $\sim 10^{9} \mathrm{~m} \mathrm{~m}^{-2}$.

(2) $\eta$ : Fluids with variable compositions and viscosities (gas, water, brine, hydrocarbon seepage, wet gouge and frictional melt) are widespread within active tectonic faults. For instance, water viscosity ranges from $\sim 1 \mathrm{mPa}$ s at subsurface conditions $(\sim 1 \mathrm{~km}$ depth) to $\sim 0.1 \mathrm{mPa}$ s at a depth of $10 \mathrm{~km}$ (considering $\eta\left(T, P_{f}\right)$, a thermal gradient of $30{ }^{\circ} \mathrm{C} \mathrm{km}^{-1}$ and a linear increase in $P_{f}$ with depth; Eppelbaum et al. 2014). Alternatively, faults can be filled with the viscous melt produced by frictional heating during earthquake coseismic slip, with a minimum viscosity of $1 \mathrm{kPa} \mathrm{s}$ (Giordano et al. 2008). Faults can contain gouge material, which can behave as a fluid with a viscosity that depends on the gouge grain size and the solid volume fraction (Otsuki et al. 2003) but generally is approximately $\sim 10 \mathrm{~Pa}$ s. Fluids commonly used in hydraulic fracturing operations in engineering reservoirs have viscosities ranging between $1 \mathrm{mPa}$ s and $1 \mathrm{~Pa} \mathrm{~s}$ (Economides 2000). Moreover, the fluid viscosity varies with in situ temperature and pressure.

(3) $P_{\text {eff }}$ : normal effective stress applied to the fault. The field stress applied on the fault plane can be described as a function of the effective principle stresses $\sigma_{1}{ }^{\prime}$ and $\sigma_{3}{ }^{\prime}$, with $\sigma_{1}{ }^{\prime}>\sigma_{3}{ }^{\prime}$. If we can consider a linear increase in pressure with depth, the effective normal stress can be written as $P_{\text {eff }}=\left(\sigma_{1}{ }^{\prime}+\sigma_{3}{ }^{\prime}\right) / 2+\left(\sigma_{1}{ }^{\prime}-\sigma_{3}{ }^{\prime}\right) / 2$ $\cos (2 \theta)$ with $\theta$ is the angle of the fault plane with the horizontal stress. Assuming Coulomb friction law, it can be shown that for an optimally oriented fault plane $\theta=\pi / 4+\phi / 2$ (Allmendinger et al. 2011b). The principal stresses $\sigma_{1}{ }^{\prime}=\max \left\{\sigma_{i}{ }^{\prime}, \sigma_{j}{ }^{\prime}\right\}, \sigma_{3}{ }^{\prime}=$ $\min \left\{\sigma_{i}{ }^{\prime}, \sigma_{j}{ }^{\prime}\right\}$, where $\sigma_{i}{ }^{\prime}=\rho_{r} g z-\rho_{f} g z$ and $\sigma_{j}^{\prime}=K \sigma_{i}^{\prime} \cdot \rho_{r}$ is the rock density and is $2700 \mathrm{~kg} \mathrm{~m}^{-3}, \rho_{f}$ is the water density and is $(1 / 3) \rho_{r}, \mathrm{~g}=9.81 \mathrm{~m} \mathrm{~s}^{-2}, z$ is the depth in $\mathrm{m}$. The ratio between the principal stresses $K$ is $\sim 0.6$ for the normal fault (lower $K$ boundary value) and it is $\sim 2.3$ (Zoback 2007) for the reverse fault (upper $\mathrm{K}$ boundary value), $\phi=\tan ^{-1} \mu$, and $\mu$ is the friction coefficient according to the Byerlee frictional law and is 0.75 (Byerlee 1978). Therefore, the effective pressure acting on a fault between 0 and $10 \mathrm{~km}$ depth ranges between 0 and $100 \mathrm{MPa}$.

(4) $V$ : Usually, the average coseismic slip rate is on the order of $1 \mathrm{~m} \mathrm{~s}^{-1}$ (Sibson 1986; Heaton 1990), but more generally, Rowe \& Griffith (2015) showed that slip rates $V$ between $10^{-4}$ and $10 \mathrm{~m} \mathrm{~s}^{-1}$ are peculiar to earthquakes. Note, we only consider the weakening mechanism activated during coseismic phase of an earthquake.

\section{CASE STUDIES OF INDUCED SEIS MICITY}

We determined the same parameters $\left(L / H^{2}, \eta, P_{\text {eff }}\right.$, and $\left.V\right)$ for eight well-documented man-induced earthquakes, which were caused by fluid injection during reservoir stimulation in various rock formations. These man-induced earthquakes were selected because they were associated with the reactivation of a pre-existing fault that occurred very close to the fluid injection borehole and because the movement between the two fault surfaces was almost planar.

(1) The fault geometrical parameter $L / H^{2}$ has been estimated based on the seismic moment of magnitude $\left(M_{0}\right)$ and the static stress drops $(\Delta \tau)$ recorded during the events. Moreover, we assumed $L$ equals the finite slip during the events $\delta$ as it is the largest possible value of $L$. For all events, we considered a circular rupture, so the fault surface ruptured area $(A)$ can be calculated as $A=\pi r^{2}$ and $\Delta \tau=(7 / 16) M_{0} / r^{3}$ (Abercrombie \& Rice 2005) with $r$ as the characteristic fault geometry. The slip $\delta(=L)$ is proportional to the moment of magnitude and rupture area:

$\delta=\frac{M_{0}}{G A}$,

where $G$ is the shear modulus ( $\sim 30 \mathrm{GPa}$ typical for the upper crustal rocks; McGarr et al. 2014). 
Therefore,

$$
L \cong \frac{M_{0}}{G \pi\left(\frac{7}{16} \frac{\mathrm{M}_{0}}{\Delta \tau}\right)^{2 / 3}},
$$

where $L$ is proportional to $M_{0}^{1 / 3}$. Finally, using the relation between the slip $\delta$ and the geometry of the fault proposed by Brodsky et al. (2011, 2016), it is possible to estimate the asperity height $\mathrm{H}$ and the wavelength $L$ for each case study:

$H=B * L^{\zeta}$

with $\zeta=0.6-1$.

(2) $\eta$. The man-induced seismicity is usually associated with the injection of water $(\eta \sim 1 \mathrm{mPa} \mathrm{s})$, brine $(\eta \sim 3-5 \mathrm{mPa} \mathrm{s})$, wastewater $(\eta \sim 3-50 \mathrm{mPa} \mathrm{s})$ and a mixture of water and proppant ( $\eta \sim 100-200 \mathrm{mPa}$ s) in many lithologies. With the exception of the Basel and Bowland Shale site (see the sections on each dedicated case), the injection procedure for all studied cases involved longterm low-pressure injections to minimize the associated seismicity. Therefore, we can consider that the viscous fluid had time to diffuse and flow throughout the whole rupture area of the fault surface. Moreover, the proppant is usually mixed with fluid and injected at high pressure and flow rate. This mixture is highly non-Newtonian (Novotny 1977), and can be considered as a fluid until the pressure injection is high (Holditch et al. 1988). After the injection, the fluid component of the initial mixture is dissipated into the rock matrix, while the proppant solid particles remain in the fracture to keep them open. Because, most of the seismic events analysed here, happened during injection of just after, we consider the fluid-proppant mixture as a fluid and not a solid. For each studied case, due to a lack of information about the precise fluid composition and fluid properties, we neglected the decrease in viscosity with increasing temperature at depth and with shear heating.

(3) $P_{\text {eff }}$. To compute the effective normal stress for each studied case, we used the field stress measured near the fault that triggered the earthquake and the fault orientation. The field stresses are usually given in terms of overburden stress $\left(S_{v}\right)$, maximum $\left(S_{H, \max }\right)$ and minimum $\left(S_{h, \min }\right)$ horizontal stresses and fault orientation. For all case studies, we reported the principal stresses (total $\sigma_{1}$ and $\sigma_{3}$ and effective $\sigma_{1}^{\prime}$ and $\sigma_{3}^{\prime}$ ) (Allmendinger et al. 2011a) as well as the fault Byerlee rupture criterion ( $\mu=0.6$ and $\mu=0.85$; Byerlee 1978) in Mohr's circles for a 3-D stress state (Fig. 2). We distinguished between the total stress state (grey circles in Fig. 2) and the effective stress state (blue circles in Fig. 2) using the fluid pressure $P_{f}$ measured at the wellbore before the beginning of the injection procedures. Shear stress $\tau$ and effective normal stress acting on the fault plane $\sigma_{n}^{\prime}$ (green points on Fig. 2) are derived from the projection of the fault plane (strike and dip angle) in the principal effective stress space, while the total normal stress $\sigma_{n}$ is obtained with the projection of the fault plane in the principal total stress space. The reported failure rupture criteria in Fig. 2 are derived from Byerlee's rule, and they are only valid for the faults and not for the rock mass.

(4) Slip rate $V$. Due to lack of information and technical difficulties in assessing the slip rate during earthquake propagation, we either fixed $V=1 \mathrm{~m} \mathrm{~s}^{-1}$ or let $V$ be unknown in our problem, and we studied its variation in the three lubrication regimes defined by the Sommerfeld number $S$. This was done only for the earthquake propagation phase, and it is not valid for the initiation of the rupture.

\subsection{Case studies}

\subsection{1 $M_{L}=3.4$ Basel, Switzerland}

The deep heat mining project (DHM), close the city of Basel in Switzerland, was initiated in 2006 to develop an enhanced geothermal system (EGS) in the granite basement. The largest event $M_{\mathrm{L}}=3.4$ occurred on 2006 December 8 at a depth of 3-4 km (Deichmann \& Giardini 2009) after $6 \mathrm{~d}$ of water injection $(\eta=1 \mathrm{mPa} \mathrm{s})$. The orientation of the principal stress was deduced from the acoustic borehole imager $\log$ in the crystalline basement section. $S_{h, \min }$ (the minimum horizontal stress) was oriented along an azimuth of $54^{\circ} \pm 14^{\circ}$, and the azimuth of $S_{H, \max }$ was $144^{\circ} \pm 14^{\circ}$ (Valley \& Evans 2019). The optimal angle between $S_{H, \max }$ and the fault strike was between $22^{\circ}$ and $30^{\circ}$, respectively (Häring et al. 2008). The estimations of $S_{H, \max }$ and $S_{h, \text { min }}$ were 160 and $74 \mathrm{MPa}$, respectively (Häring et al. 2008). The fluid pressure $P p$ was estimated to be approximately 9.8 MPa (Goertz-Allmann et al. 2011). We estimated an effective normal stress of $88.45 \pm 5.37 \mathrm{MPa}$ acting on the fault (Fig. 2a). The radius of the rupture area was approximately $101 \mathrm{~m}$, and the seismic moment of the main event was $1.60 \times 10^{14} \mathrm{~N} \mathrm{~m}$ (McGarr et al. 2014). Following eqs (1) and (2) the coseismic slip of the event is estimated to be $0.156 \mathrm{~m}$, and the asperity height is $H=$ $0.16-0.45 \mathrm{~mm}$. The geometry parameters are $L / H^{2}=(3.58 \pm 1.41)$ $10^{6} \mathrm{~m} \mathrm{~m}^{-2}$.

\subsection{2 $M_{w}$ 4.3 Paradox Basin, Colorado, USA}

Since 1991, the Paradox Valley Unit project was involved in the injection of brine in southwest Colorado. On 2000 May 27, an earthquake of $M_{\mathrm{w}} 4.3$ was recorded in the Paradox Valley in Colorado. The Paradox Valley project consisted of an $\sim 100 \mathrm{~m}$ depth shallow well, which, from January 2002, was mostly used for the injection of Paradox Valley Brine (PVB) with freshwater (70 per cent PVB-30 per cent freshwater) or 100 per cent PVB (Ake et al. 2005). The two mixtures had viscosities ranging between 0.001 and $0.003 \mathrm{~Pa}$ s. The Paradox Basin close to the Paradox Valley is a collapsed diapiric salt anticline. Well logs from nearby wells, seismic reflection profiles and in situ studies (Bremkamp \& Harr 1988) indicated the presence of the Wray Mesa fault, which trends subparallel to the strike of the Paradox Valley. The injection well was sited to optimize fluid migration into and along these faults. The inversion of the focal mechanisms of Paradox valley-induced earthquakes showed an orientation of the maximum horizontal stress $S_{H, \max }$ of $\mathrm{N}^{\circ} 5^{\circ} \mathrm{W}-$ $\mathrm{N} 54^{\circ} \mathrm{W}$ (Block et al. 2015) with a stress gradient at a depth of $23.95 \times 10^{-3} \mathrm{MPa} \mathrm{m}^{-1}$ for $S_{H, \text { max }}$ and at $16.2 \times 10^{-3} \mathrm{MPa} \mathrm{m}^{-1}$ for $S_{h, \min }$ (Ake et al. 2005). The earthquake depth was between 3.5 and $6.5 \mathrm{~km}$. The hydrostatic pressure gradient was $9.95 \times 10^{-3} \mathrm{MPa}$ $\mathrm{m}^{-1}$ in this area, while the vertical pressure gradient was $16.8 \times$ $10^{-3} \mathrm{MPa} \mathrm{m}^{-1}$ (King et al. 2014). Considering that the activated fault was striking at $\mathrm{N} 78^{\circ} \mathrm{E}$ and dipping at $84^{\circ}$, the normal stress acting on the fault plane ranged between 60 and $99 \mathrm{MPa}$, while the effective normal stress was $32.5 \pm 3.5 \mathrm{MPa}$ (Fig. 2b). The moment magnitude of the earthquake was $3.16 \times 10^{15} \mathrm{~N} \mathrm{~m}$ (McGarr et al. 2014), and the rupture radius was $\sim 0.4-0.6 \mathrm{~km}$ (Yeck et al. 2015). Using the relation between seismic moment, rupture radius and slip, it was possible to estimate the coseismic slip of the fault $(0.09-0.20 \mathrm{~m})$, the fault geometry parameter of $H=0.1-0.2 \mathrm{~mm}$ and that $L / H^{2}$ is $(4.02 \pm 0.59) 10^{6} \mathrm{~m} \mathrm{~m}^{-2}$. 
(a) Basel

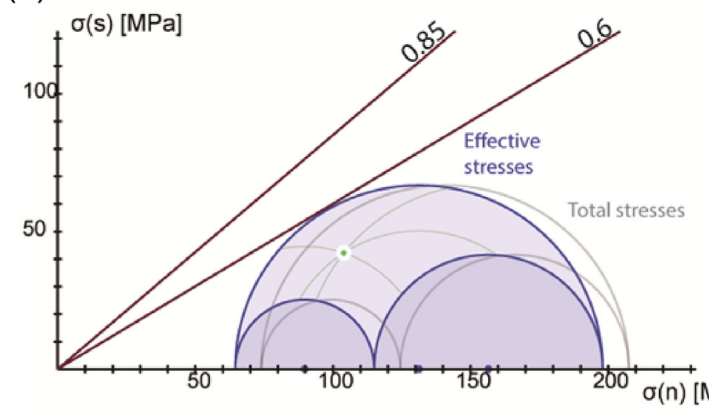

(c) Youngstown

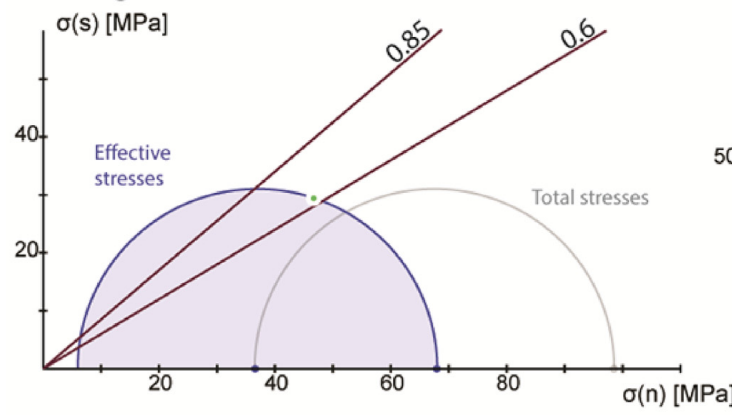

(b) Paradox Valley

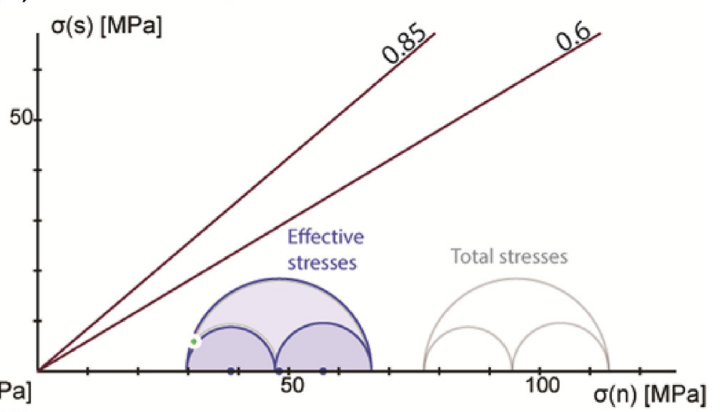

(d) Prague

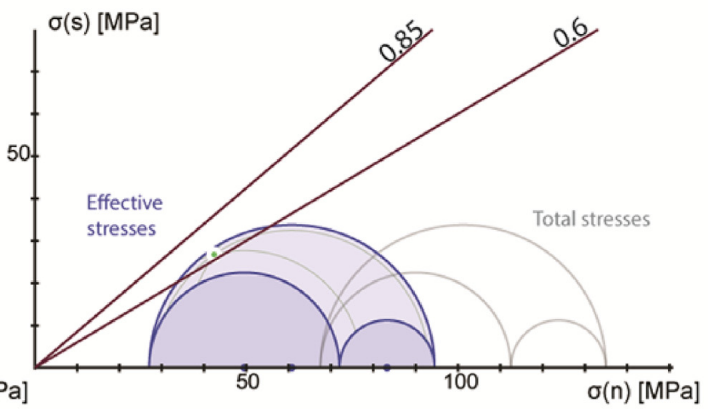

(e) Timpson

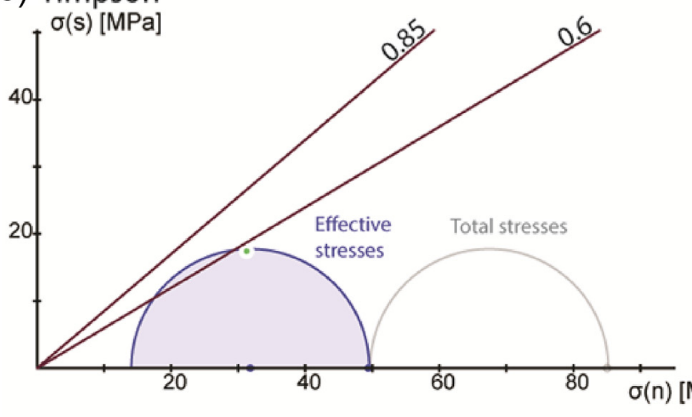

(f) Pawnee

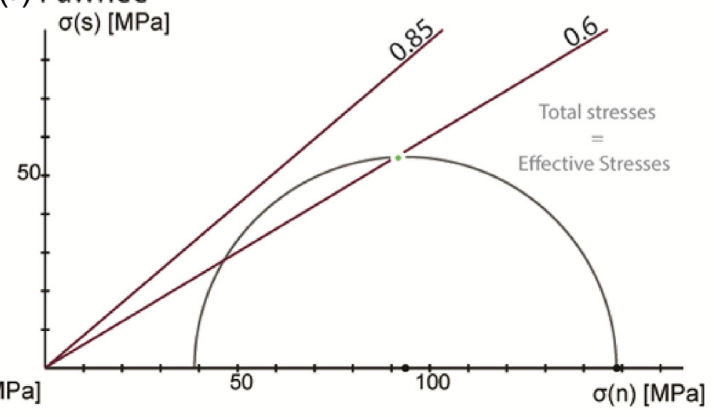

(g) Fox Creek

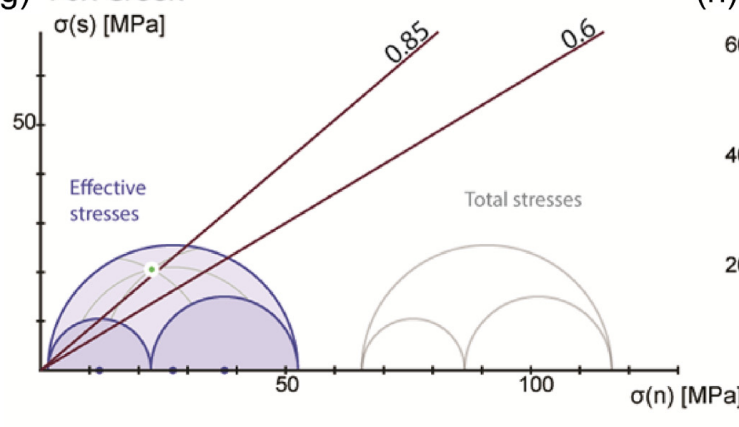

(h) Bowland Shale

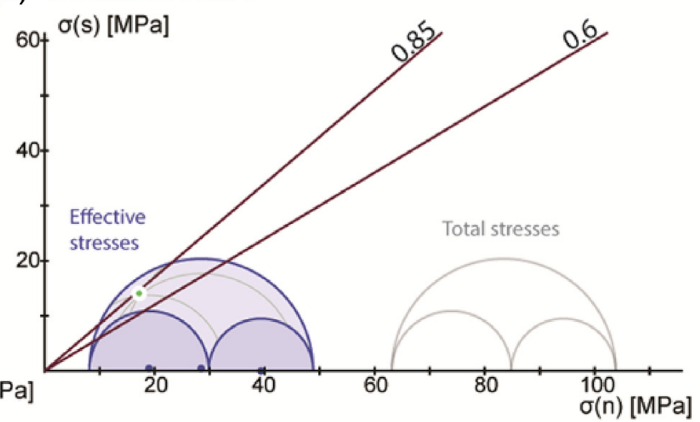

Figure 2. Mohr-Coulomb circles representing the average in situ stress, fault orientation and Byerlee failure criteria for the (a) Basel earthquake, (b) Paradox Valley earthquake, (c) Youngstown earthquake, (d) Prague earthquake, (e) Timpson earthquake, (f) Pawnee earthquake, (g) Fox Creek earthquake and (h) Bowland Shale. The red lines are the failure envelope for the fault following the Byerlee law. The grey circles are the average Mohr-Coulomb circles without fluid pressure (total stresses), and the blue circles are the average Mohr-Coulomb circles with estimated hydrostatic fluid pressure (effective stresses). The green points are the resolved effective stresses for the average specified activated fault.

\subsection{3 $M_{w}$ 3.9 Youngstown, Ohio, USA}

Since 2010, five deep injection wells have been used for the injection of brine that is used for hydraulic fracturing in the area of Youngstown. On 2011 December 31, an earthquake of magnitude $M_{\mathrm{w}} 3.9$ was detected in that area following the injection through a well into the Precambrian granite at a total depth of $2802 \mathrm{~m}$
(Kim 2013). The viscosity of the injected water was between $\eta=$ 0.001-0.003 $\mathrm{Pa}$ s. The earthquake hypocentre depth was between 3.55 and $3.68 \mathrm{~km}$ (ODNR 2012). The results of the focal mechanism modelling and the inversion indicate that the focal mechanism of the event is predominantly strike-slip faulting with a strike of $265^{\circ}$, dip of $72^{\circ}$ and seismic moment of $M_{0}=8.30 \pm 8.010^{14} \mathrm{Nm}$ 
(Kim 2013). The estimation of normal stress on the plane fault is $30.2 \mathrm{MPa}$ (Kim 2013). Considering the fluid pressure of $30.5 \mathrm{MPa}$, the effective normal stress is $46.9 \mathrm{MPa}$ (Fig. 2c).

The rupture area was $410^{5} \mathrm{~m}^{2}$ (Morris et al. 2017). Considering a circular rupture, we can estimate a radius of the rupture area to be approximately $357 \mathrm{~m}$, a coseismic slip of $0.09 \pm 0.03 \mathrm{~m}$ and an asperity size of $H \sim 0.19 \mathrm{~mm}$. The geometry of the fault can be described as $L / H^{2}=(8.32 \pm 0.23) 10^{5} \mathrm{~m} \mathrm{~m}^{-2}$.

\subsection{4 $M_{w}$ 5.7 Prague, Oklahoma, USA}

The oil and gas reservoirs in the northern region of Oklahoma have been exploited since the early 20 th century. The area was often subjected to induced earthquakes caused by wastewater injection $(\eta=$ 30-50 mPa s). Three earthquakes with $M_{\mathrm{w}}$ values of 5.0, 5.7 and 5.0 occurred near Prague, Oklahoma, on 2011 November 5, 6 and 8 in the Wilzetta fault system at hypocentral depths of 3.1, 5.2 and $5 \mathrm{~km}$, respectively (Keranen et al. 2013). Walsh \& Zoback (2016) performed stress inversions using a focal mechanism analysis of 15 earthquakes near Prague to determine stress orientations and magnitudes in the area. The overburden gradient was $S_{v}=25 \mathrm{MPa} \mathrm{km}^{-1}$, the fluid pressure gradient was $P_{p}=9 \mathrm{MPa} \mathrm{km}^{-1}$ and the static friction coefficient was $\mu=0.7$. The fault regime was found to be strike-slip, and the orientation of the maximum principal stress was found to be $\mathrm{N} 83^{\circ} \mathrm{E}$. The minimum and maximum horizontal stress gradients were estimated as $S_{h, \text { min }}=15 \mathrm{MPa} \mathrm{km}^{-1}$ and $S_{H, \text { max }}=$ $30 \mathrm{MPa} \mathrm{km}^{-1}$, respectively.

Considering the principal stresses magnitude and orientation, the normal stress acting on the fault can range between 70.4 and $88 \mathrm{MPa}$, while the effective normal stress was $38.7 \pm 2.15 \mathrm{MPa}$ (Fig. 2d).

The seismic moment of the main event was between $3.37 \times 10^{17}$ $\mathrm{Nm}$ (Sun \& Hartzell 2014) and $3.92 \times 10^{17} \mathrm{Nm}$ (McGarr et al. 2014 ) with a stress drop $\Delta \tau=6.75-27.64 \mathrm{MPa}$ (Cramer 2017). Therefore, considering a circular rupture, the coseismic slip was $0.77-0.16 \mathrm{~m}$, and the asperity height was $H \sim 1.88 \mathrm{~mm}$. These values were comparable with those proposed by Sun \& Hartzell (2014). For the Prague main event, $L / H^{2}$ was $(4.87 \pm 2.12) 10^{5} \mathrm{~m}$ $\mathrm{m}^{-2}$

\subsection{5 $M_{w}$ 4.8 Timpson, Texas, USA}

The 2012 May $17 M_{\mathrm{w}} 4.8$ earthquake near Timpson, east Texas, occurred after wastewater was injected $(\eta=30-50 \mathrm{mPa}$ s) into two nearby disposal wells into the Rodessa Formation. Epicentres of smaller events following the $M_{\mathrm{w}} 4.8$ event and located using a portable seismic array were aligned parallel to a fault that was previously mapped using seismic reflection surveys (Frohlich et al. 2014). The focal depths of these events ranged between 2.5 and $4.6 \mathrm{~km}$ (Frohlich et al. 2014). The fault dipped at approximately $63^{\circ} \pm 2^{\circ}$ to the southwest. An average gradient of the vertical stress $S_{v}$ of $24 \mathrm{MPa} \mathrm{km}^{-1}$ was calculated by (Thiercelin \& Plumb 1994). The minimum horizontal stress $S_{h \text {, min }}$ and the fluid pressure had gradients of 14 and $10.08 \mathrm{MPa} \mathrm{km}^{-1}$, respectively (Fan et al. 2016). It was reasonable to suppose that $S_{H, \max }=S_{v}$ (Fan et al. 2016); that is, a transitional stress state exists between a strike-slip and normal faulting stress regime. Using the procedure proposed in Fan et al. (2016), we determined the effective normal stress acting on the fault at the hypocentral depth of 19-39.5 MPa (Fig. 2e).

The seismic moment of the event was $2.21 \times 10^{16} \mathrm{~N} \mathrm{~m}$ (McGarr et al. 2014) and the stress drop was $\Delta \tau=12.32-33.80 \mathrm{MPa}$ (Cramer 2017). Considering a circular rupture, the radius of the rupture area was $698 \pm 22.1 \mathrm{~m}$, the coseismic slip was $0.40 \pm 0.07 \mathrm{~m}$ and the asperity height was $H \sim 1.93 \mathrm{~mm}$. The geometry of the fault can be described as $L / H^{2}=(1.83 \pm 0.90) 10^{6} \mathrm{~m} \mathrm{~m}^{-2}$.

\subsection{6 $M_{w}$ 5.8 Pawnee, Oklahoma, USA}

Since 2009, saltwater disposal $(\eta=30-50 \mathrm{mPa}$ s) in the northcentral area of Oklahoma has caused an increase in the background seismicity in the area. In particular, the 2016 September 3, $M_{\mathrm{w}}$ 5.8 Pawnee main shock resulted from a left-lateral slip across an unmapped fault (Pawnee fault or Sooner Lake fault), striking westnorthwestward. The main shock was located at a depth of $5.6 \mathrm{~km}$ with an uncertainty of $0.7 \mathrm{~km}$ (Pollitz et al. 2017). The stress orientation obtained from both the wellbore data and focal mechanism inversion showed a direction $\mathrm{N} 83^{\circ} \pm 3^{\circ} \mathrm{E}$ with a plunge of $14.9^{\circ}$ (Alt $\&$ Zoback 2017). The fault had a strike of $283^{\circ}$ and dip of $77^{\circ}$. The effective normal stress gradient can be assumed to be equal to $17 \mathrm{MPa} \mathrm{km}^{-1}$ (Huang et al. 2017). The depth of the causative fault involved in the main shock remains poorly constrained (Grandin et al. 2017), but the aftershock seismicity was concentrated at $\sim 6 \mathrm{~km}$ depth, and the majority of earthquakes in north-central Oklahoma are at 5-6 km depth (McNamara et al. 2015).

The stress drop $\Delta \tau$ during the main event was between 10.15 and 34.27 MPa (Cramer 2017). The seismic moment of the main event was $4.67 \times 10^{17} \mathrm{~N} \mathrm{~m}$. Considering a circular rupture, the radius of the rupture area involved in the main event was $2.1-2.4 \mathrm{~km}$. The slip associated with the event was $1.09 \pm 0.21 \mathrm{~m}$, and the asperity size was $H \sim 10.25 \mathrm{~mm}$. We can describe the geometry of the fault as $L / H^{2}=(7.48 \pm 3.72) 10^{5} \mathrm{~m} \mathrm{~m}^{-2}$.

\subsection{7 $M_{w}=4.1$ Fox Creek, Alberta, $C A$}

The Duvernay Formation, close to the Fox Creek area, hosts hydrocarbon resources, which have become economically feasible since June 2010. The $M_{\mathrm{w}} 4.1$ earthquake on 2015 June 13 was recorded in the Fox Creek area in the Duvernay Formation. The area was characterized by the presence of more than 290 wells between depths of 2.6 and $4.0 \mathrm{~km}$. During the site hydrofracking procedure, the stimulation phase (e.g. injection of fluid) was merged with the postprocess (e.g. shut-in) phases. The main event occurred during the shut-in phase; the average mean pressures, pumping rates, total pumped fluid volume and proppant weight in the well for individual stages were $62.6 \mathrm{MPa}, 9.4 \mathrm{~m}^{3} \mathrm{~min}^{-1}, 1200 \mathrm{~m}^{3}$, and $240 \mathrm{t}$, respectively (Schultz et al. 2017). The fluid viscosity was estimated as $\eta$ $=0.1-0.2 \mathrm{~Pa} \mathrm{~s}$.

Focal mechanisms suggested strike-slip motion on a subvertical fault (strike of $354^{\circ}$ and dip of $83^{\circ}$; Wang et al. 2016; Schultz et al. 2017), and the inversion of the moment tensor suggested a $3-4 \mathrm{~km}$ hypocentral depth (Wang et al. 2016).

The azimuth of the field stress was $\sim \mathrm{N} 45^{\circ} \mathrm{E}$ (Schultz et al. 2017). The maximum horizontal stress $S_{H, \max }$ plunge was $35^{\circ}-42^{\circ}$, and its gradient was estimated to be $33 \pm 2 \mathrm{kPa} \mathrm{m}^{-1}$ (Shen et al. 2018). The minimum stress to depth ratio was constrained between $\sim 17$ and $\sim 21 \mathrm{kPa} \mathrm{m}^{-1}$, and the fluid pressure to depth ratio ranged from $\sim 10$ to $\sim 21 \mathrm{kPa} \mathrm{m}^{-1}$ (Shen et al. 2018). The fault plane was identified by strikes and dips of $354^{\circ} \mathrm{N}$ and $83^{\circ}$, respectively.

Considering the orientation of the principal stresses and of the plane, the normal stress and the effective normal stress acting on the fault can range between 74.2 and $97.6 \mathrm{MPa}$ and 20-22 MPa, respectively (Fig. $2 \mathrm{~g}$ ). 


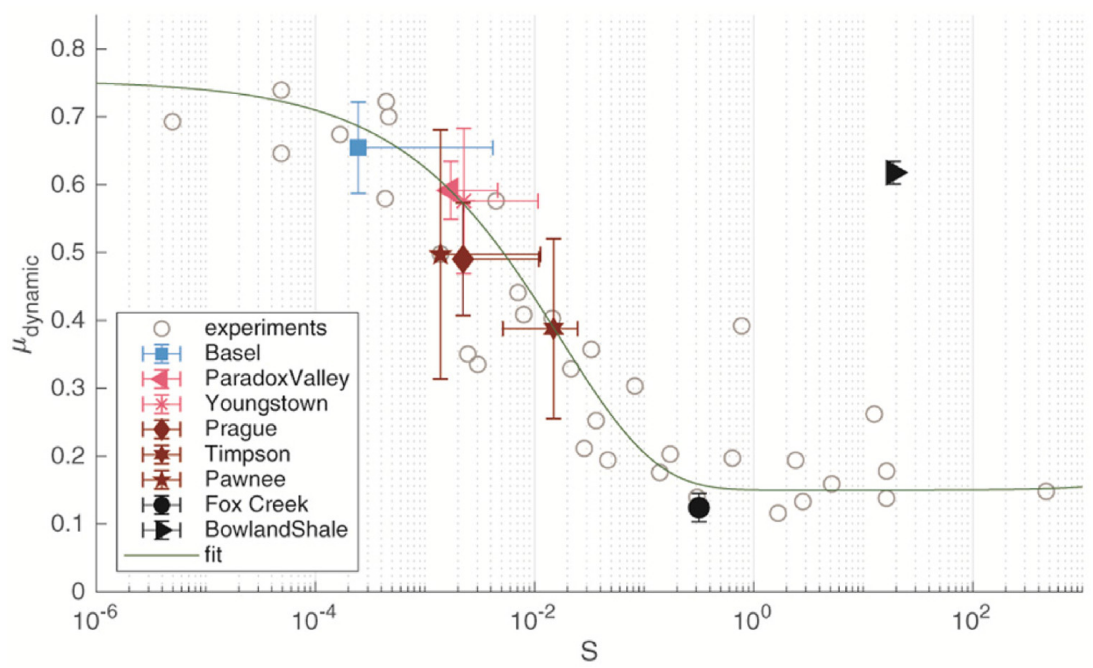

Figure 3. Estimated dynamic friction coefficient versus the Sommerfeld number for induced seismicity cases. The grey empty circles are the experimental data of Cornelio et al. (2019), while the full markers are the estimated values of dynamic friction and Sommerfeld number for the cases studied (see the legend in the figure). The three lubrication regimes (BL, ML, and EHD) are delimited by the vertical black dashed lines. The dynamic friction coefficient $\mu_{\text {dyn }}$ in the three lubrication regimes decays from 0.75 in the BL regime to 0.1 at the boundary between the mixed and fully lubricated regimes.

(a)

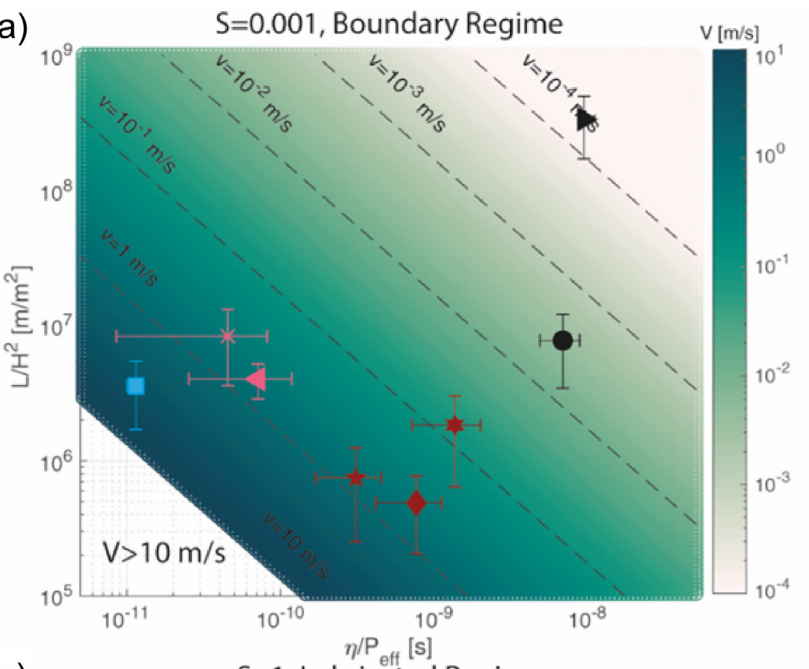

(c)

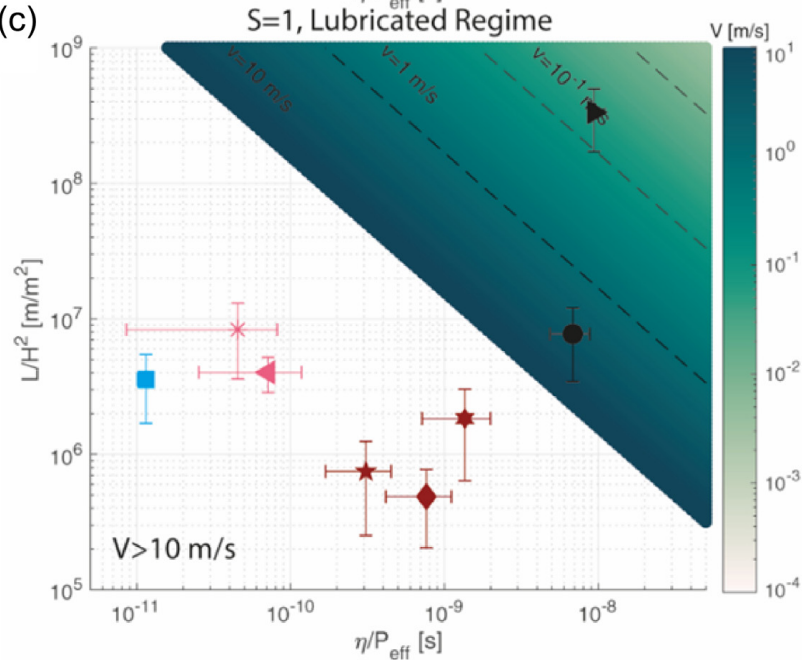

(b) $\quad \mathrm{S}=0.01$, Mixed Regime
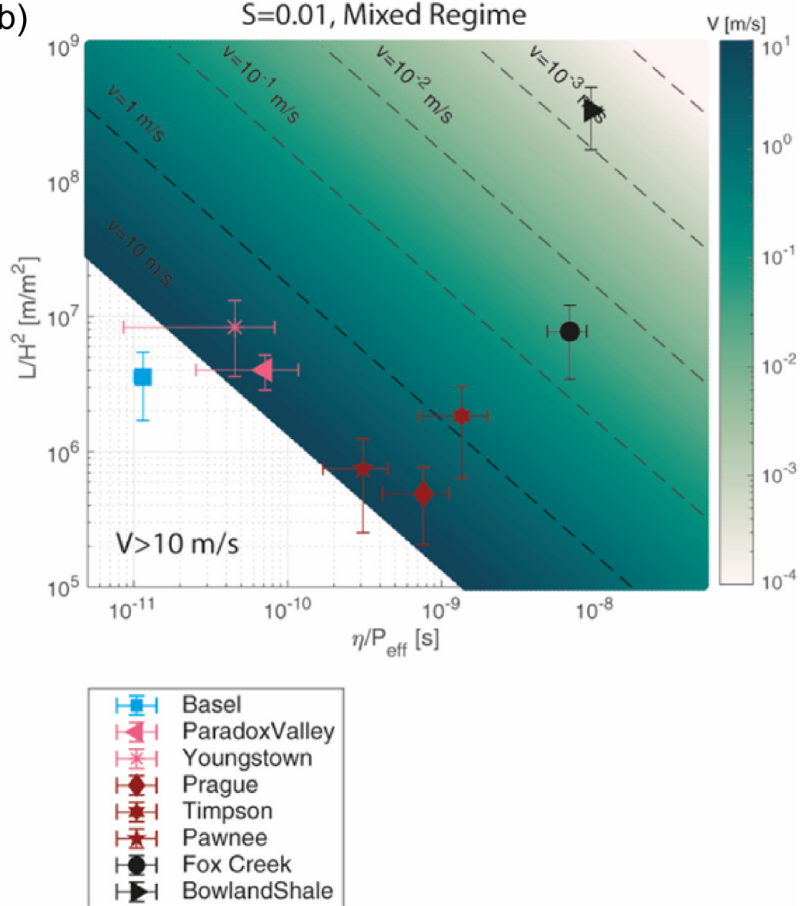

Figure 4. The multiaxis plot of the Sommerfeld number for the man-induced seismicity range of values and real events for (a) $S=0.001$ (end of the boundary lubrication regime), (b) $S=0.01$ (in the mixed lubrication regime) and (c) $S=1$ (beginning of the mixed lubrication regime). The blank areas of the graphs show the combination of $\eta / P_{\text {eff }}$ and $L / H^{2}$, which required $V>10 \mathrm{~m} \mathrm{~s}^{-1}$ to obtain the imposed $S$ values $(S=0.001, S=0.01$ and $S=1)$ 
Table 1. Summary of the case study reporting the magnitude, viscosity of the injected fluid, average values of depth, effective stress $P_{\text {eff }}$, moment of magnitude $M_{0}$, stress drop $\Delta \tau$, slip of the event $\delta=L$, asperity size of the fault $\mathrm{H}$ and estimated $\mathrm{S}$ for slip-rate $\mathrm{V}=1 \mathrm{~m} / \mathrm{s}$

\begin{tabular}{|c|c|c|c|c|c|c|c|c|c|c|}
\hline Place & Mag & $\begin{array}{c}\eta \\
(\mathrm{mPa} \mathrm{s})\end{array}$ & $\begin{array}{c}\text { Depth } \\
(\mathrm{km})\end{array}$ & $\begin{array}{c}\sigma_{n} \\
(\mathrm{MPa})\end{array}$ & $\begin{array}{c}P_{\text {eff }} \\
(\mathrm{MPa})\end{array}$ & $\begin{array}{c}M_{0} \\
(1 \mathrm{e} 14 \mathrm{~N} \mathrm{~m})\end{array}$ & $\begin{array}{c}\Delta \tau \\
(\mathrm{MPa})\end{array}$ & $\begin{array}{c}L \\
(\mathrm{~m})\end{array}$ & $\begin{array}{c}H \\
(\mathrm{~mm})\end{array}$ & $S\left(V=1 \mathrm{~m} \mathrm{~s}^{-1}\right)$ \\
\hline Basel & 3.4 & 1 & 4.7 & 97.95 & 88.45 & 1.60 & 6.81 & 0.16 & 0.31 & $2.46 \times 10^{-4}$ \\
\hline Paradox Valley & 4.3 & $10-30$ & 4.2 & 79.75 & 32.49 & 31.60 & 10.00 & 0.14 & 0.18 & $1.72 \times 10^{-3}$ \\
\hline Prague & 5.6 & $30-50$ & 4.5 & 79.17 & 38.67 & 3645.00 & 17.20 & 0.57 & 1.88 & $2.23 \times 10^{-3}$ \\
\hline Timpson & 4.7 & $30-50$ & 3.5 & 64.85 & 29.21 & 221.00 & 23.06 & 0.48 & 1.93 & $1.49 \times 10^{-2}$ \\
\hline Pawnee & 5.7 & $30-50$ & 5.5 & 93.50 & 93.50 & 4670.00 & 22.21 & 0.98 & 10.25 & $1.39 \times 10^{-3}$ \\
\hline
\end{tabular}

The seismic moment of the event was $3.9 \times 10^{15}-8.343 \times$ $10^{15} \mathrm{~N} \mathrm{~m}$ (Atkinson et al. 2016), and the stress drop $\Delta \tau=5.45$ $\pm 1.28 \mathrm{MPa}$ (Clerc et al. 2016). Using eqs (1) and (2), we computed a rupture radius between 654.6 and $694.31 \mathrm{~m}$, a slip between 0.07 and $0.12 \mathrm{~m}$ and an asperity size of $H \sim 0.19 \mathrm{~mm}$. Using the relation between the slip and the geometry of the fault (eqs 1 and 2), we computed $L / H^{2}=(7.74 \pm 1.36) 10^{6} \mathrm{~m} \mathrm{~m}^{-2}$.

\subsection{8 $M_{w} 2.3$ Bowland Shale, Lancashire, UK}

In spring 2011, Caudrilla Resources conducted a vertical multistage hydraulic fracture operation into the Carboniferous Bowland Shales in Lancashire. The 2011 May 27 earthquake of magnitude 2.3 was recorded in the Bowland Shale Formation after injection of a mixture of fluid and proppant ( $\eta=0.1-0.2$ Pa.s). The focal mechanism was strike-slip failure. Consistent with the regional Carboniferous faulting observed in the seismic reflection data Eisner et al., 2013, we considered the fault nodal plane dipping at $70^{\circ}$ with a strike of $40^{\circ}$. The maximum horizontal stress direction, deduced from both the drilling-induced tensile fractures and the fast shear wave arrival, had an orientation of $30^{\circ}$ to this probable fault plane, which was identified from the focal mechanism and the 3-D seismic data. The orientation of the maximum horizontal stress was a plunge of $175^{\circ}$ $205^{\circ}$ and trend of $20^{\circ}-25^{\circ}$. The $S_{H, \max }$ magnitude in the Bowland Shale was approximately $28.33-29.46 \mathrm{MPa} \mathrm{km}^{-1}$, and the average minimum stress was approximately $17-18.3 \mathrm{MPa} \mathrm{km}^{-1}$, while the vertical stress gradient was approximately $23.57 \mathrm{MPa} \mathrm{km}^{-1}$ (de Pater \& Baisch 2011). The normal stress acting on the fault plane ranged between 65.42 and $72.41 \mathrm{MPa}$ (Fig. 2h). Considering that a fluid pressure at the hypocentral depth of $3.5 \mathrm{~km}$ was approximately $P_{p}=55 \mathrm{MPa}$ (de Pater \& Baisch 2011), we can estimate the effective normal stress acting on the fault as 13.7-25.5 MPa (Fig. 2h).

The seismic moment of the event was $3.20 \times 10^{12} \mathrm{~N} \mathrm{~m}$ (McGarr et al. 2014). Considering a circular rupture, the radius of the rupture area can be estimated to be 53.9 and $53.8 \mathrm{~m}$ (Green et al. 2012) with a stress drop of 6.7-9.1 MPa. The coseismic slip associated with the event was estimated to be approximately $0.01 \mathrm{~m}$ and $H \sim 0.008 \mathrm{~mm}$. Considering the relation between coseismic slip and fault geometry (eqs 1 and 2), we can estimate $L / H^{2}=(3.35 \pm 1.22) 10^{8} \mathrm{~m} \mathrm{~m}^{-2}$.

Summary of the parameters for the analyzed case studies are reported in Table 1.

\section{COMPARISON WITH THEORETICAL AND EXPERIMENTAL FRAMEWORKS}

Fluid overpressure generated by the injection of water, brine, wastewater or proppants acts against normal stress, reduces the effective normal stress and facilitates fault reactivation (King Hubbert \& Rubey 1959). The failure conditions to initiate ruptures are often evaluated by using the isotropic Mohr-Coulomb theory, where the critical shear stress $\left(\tau_{\text {crit }}\right)$ is given by $\tau_{\text {crit }}=\mu\left(\sigma_{n}-P_{p}\right)$, where $\sigma_{n}$ is the total normal stress and $P_{p}$ is the fluid pressure. Large overpressure can potentially activate unfavourable oriented faults (Fig. 2b).

However, the Mohr-Coulomb theory only describes the onset of fault reactivation, and it ignores the significant weakening and lubrication that faults experience toward seismic slip (Reches \& Lockner 2010), which is mandatory to understand fluid-induced earthquake propagation. Until now, lubrication during coseismic sliding (i.e. sliding velocity $V \sim 1 \mathrm{~m} \mathrm{~s}^{-1}$ ) has been interpreted as a consequence of a number of processes, such as flash heating (Rice 2006) and melting (Rempel \& Rice 2006), decomposition reactions (Han et al. 2007), superplastic flow (De Paola et al. 2015; Green II et al. 2015) and thermal pressurization (Rice 2006; Violay et al. 2015; Acosta et al. 2018); many of these processes are actually thermally triggered (Di Toro et al. 2011 and references therein). Recently, Cornelio et al. (2019) proposed that a single mechanism, the EHD, can explain fault weakening when fluids with high viscosity are involved. The EHD efficiency is governed by a dimensionless parameter called the Sommerfeld number $(S)$. Determining the parameters that define the Sommerfeld number for fluid-induced earthquakes is not always possible due to the lack of seismological monitoring of the events. Here, we analysed eight well-documented case studies of induced seismicity for which it was possible to determine the parameters required in the calculation of the $S$ number.

The $S$ number of these events is now compared with those expected by theory and experimental investigations. The coseismic slip rate $V$ is fixed at $1 \mathrm{~m} \mathrm{~s}^{-1}$ (Sibson 1986; Heaton 1990; Fig. 3). Considering the static stress drop $\Delta \tau$ as the upper bound for the dynamic stress drop during the event, we computed the maximum dynamic friction as

$\mu_{\mathrm{dyn}}\left(\alpha \sigma_{n}-\Delta \tau\right) / \sigma_{n}$,

where

$\alpha=0.65-0.8$ is the static friction coefficient defined by Byerlee's law. Fig. 3 reports the eight case studies as well as the theoretical prediction and experimental data of Cornelio et al. (2019). The vertical dashed lines define the limit of the three lubrication regimes. Remarkably, the eight case studies follow the same trend as the experimental and theoretical predictions. For most of the analysed events, the event occurs under the ML regime, in which the load is partially supported by the fluid layers and partially supported by the solid asperities present on the fault. These events are also characterized by an intermediate viscosity of injected fluids (wastewater 
and brine). The events in which proppant was injected appear to be more on the right part of Fig. 3, close to the transition between the mixed and the EHD lubrication regime or in the fully lubrication regime where the stress is only supported by the fluid film on the slip surface.

To investigate the possible effect of a slip-rate $V$ lower or higher than $1 \mathrm{~m} \mathrm{~s}^{-1}$, we use a three-axis plot (Fig. 4); in the background, we reported the possible variation in the coseismic slip-rate with the colour bar (from $10^{-4}$ to $10 \mathrm{~m} \mathrm{~s}^{-1}$ ), the geometrical factor $L / H^{2}$ on the $y$-axis and the fluid parameters $\eta / P_{\text {eff }}$ on the $x$-axis in the characteristic range of values of the BL regime ( $S=0.001$, Fig. $4 \mathrm{a})$, in the ML regime $(S=0.01$, Fig. 4 b) and in the EHD lubrication regime $(S=1$, Fig. 4 c).

Fig. 4 shows the following:

(1) The Basel main event, produced by the injection of water (blue marker), cannot be explained by the EHD theory. In fact, the Sommerfeld number for this event, considering the typical coseismic slip rate $\left(V<10 \mathrm{~m} \mathrm{~s}^{-1}\right)$, ranges within the BL regime, and the EHD theory cannot explain the estimated drop in the shear stress of 12.5 MPa (Goertz-Allmann et al. 2011).

(2) The injection of proppant (black markers), that is, the Fox Creek and Bowland Shale formation locations, can allow the fault to slip into the fully EHD lubrication regime, associated with a smaller friction coefficient (i.e. a lower fault strength).

(3) Most of the man-induced events studied in this paper involve the injection of wastewater (red markers) and brine (pink markers), which is characterized by an intermediate viscosity. In the studied cases, the lower viscosity of the wastewater and that of the brine compared to the proppant do not allow the fault to reach the EHD lubrication regime. In these cases, sliding during the man-induced event could occur in the ML regime (Fig. 4b).

\section{CONCLUSIONS}

We performed a parametric analysis of the parameters that describe the Sommerfeld number, which is a key parameter assessing the effectiveness of EHD during seismic sliding. We analysed eight well-documented cases of induced seismicity events by considering EHD theory. We observed the following:

(1) Under the assumption of a constant coseismic slip rate $V=$ $1 \mathrm{~m} \mathrm{~s}^{-1}$, the eight induced seismicity cases follow the decay of the dynamic friction coefficient as a function of the dimensionless Sommerfeld number, which was predicted by theory and demonstrated experimentally by Cornelio et al. (2019).

(2) Removing the assumption of a constant coseismic slip rate, earthquakes triggered by the injection of proppant can achieve full EHD lubrication, whereas most of the other cases where fluids with intermediate viscosities were injected fall into the ML regime. Only earthquakes triggered by water injection fall into the BL regime and cannot be explained in the framework of the EHD theory.

In conclusion, in some conditions of effective normal stress $P_{\text {eff }}$ and fault geometry $L / H^{2}$, the high viscosity of the injected fluid during hydraulic reservoir stimulation can enhance fault weakening through EHD lubrication processes and facilitate the rupture propagation of man-induced earthquakes.

\section{ACKNOWLEDGEMENTS}

This research is funded by the European Research Council Starting Grant project 757290-BEFINE. The authors acknowledge EPFL for support. The authors acknowledge SFOE (Swiss Federal Office of Energy) for the EDGAR project. The authors thank Dr Giorgetti and Dr Passelègue for constructive comments about the manuscript.

\section{REFERENCES}

Abercrombie, R.E. \& Rice, J.R., 2005. Can observations of earthquake scaling constrain slip weakening? Geophys. J. Int., 162(2), 406-424.

Acosta, M., Passelègue, F.X., Schubnel, A. \& Violay, M., 2018. Dynamic weakening during earthquakes controlled by fluid thermodynamics, Nat. Commun., 9(1), 3074, doi:10.1038/s41467-018-05603-9.

Ake, J., Mahrer, K., O'Connell, D. \& Block, L., 2005. Deep-injection and closely monitored induced seismicity at Paradox Valley, Colorado, Bull. seism. Soc. Am., 95(2), 664-683.

Allmendinger, R.W., Cardozo, N. \& Fisher, D.M., 2011a. Stress, in Structural Geology Algorithms: Vectors and Tensors, pp. 98-119, eds. Fisher, D.M., Cardozo, N. \& Allmendinger, R.W., Cambridge Univ. Press.

Allmendinger, R.W., Cardozo, N. \& Fisher, D.M., 2011b. Tensors, in Structural Geology Algorithms: Vectors and Tensors, pp. 81-97, eds. Fisher, D.M., Cardozo, N. \& Allmendinger, R.W., Cambridge Univ. Press.

Alt, R.C. \& Zoback, M.D., 2017. In situ stress and active faulting in Oklahoma, Bull. seism. Soc. Am., 107(1), 216-228.

Atkinson, G.M. et al., 2016. Hydraulic fracturing and seismicity in the western Canada sedimentary basin, Seismol. Res. Lett., 87(3), 631-647.

Block, L.V., Wood, C.K., Yeck, W.L. \& King, V.M., 2015. Induced seismicity constraints on subsurface geological structure, Paradox Valley, Colorado, Geophys. J. Int., 200(2), 1172-1195.

Bremkamp, W. \& Harr, C.L., 1988. Area of least resistance to fluid movement and pressure rise, Paradox Valley Unit, Salt Brine Injection Project, Bedrock, Colorado, U.S. Bureau of Reclamation.

Brodsky, E.E. \& Kanamori, H., 2001. Elastohydrodynamic lubrication of faults, J. geophys. Res., 106(B8), 16357-16374.

Brodsky, E.E., Gilchrist, J.J., Sagy, A. \& Collettini, C., 2011. Faults smooth gradually as a function of slip, Earth planet. Sci. Lett., 302(1-2), 185-193.

Brodsky, E.E., Kirkpatrick, J.D. \& Candela, T., 2016. Constraints from fault roughness on the scale-dependent strength of rocks, Geology, 44(1), 1922 .

Byerlee, J., 1978. Friction of rocks, Pure appl. Geophys., 116(4-5), 615-626.

Clerc, F., Harrington, R.M., Liu, Y. \& Gu, Y.J., 2016. Stress drop estimates and hypocenter relocations of induced seismicity near Crooked Lake, Alberta, Geophys. Res. Lett., 43(13), 6942-6951.

Cornelio, C., Spagnuolo, E., Di Toro, G., Nielsen, S. \& Violay, M., 2019. Mechanical behaviour of fluid-lubricated faults, Nat. Commun., 10(1), 1274, doi:10.1038/s41467-019-09293-9.

Cornelio, C., Passelègue, F.X., Spagnuolo, E., Di Toro, G. \& Violay, M., 2020. Effect of fluid viscosity on fault reactivation and coseismic weakening, J. geophys. Res., 125(1), 1-18.

Cramer, C.H., 2017. Brune stress parameter estimates for the $2016 M_{\mathrm{w}}$ 5.8 Pawnee and other Oklahoma earthquakes, Seismol. Res. Lett., 88(4), $1005-1016$

Deichmann, N. \& Giardini, D., 2009. Earthquakes Induced by the Stimulation of an Enhanced Geothermal System below Basel (Switzerland), Seismol. Res. Lett., 80(5), 784-798.

De Paola, N., Holdsworth, R.E., Viti, C., Collettini, C. \& Bullock, R., 2015. Can grain size sensitive flow lubricate faults during the initial stages of earthquake propagation? Earth planet. Sci. Lett., 431, 48-58.

de Pater, C.J.J. \& Baisch, S., 2011. Geomechanical study of Bowland Shale seismicity, Synthesis Report.

Di Toro, G. et al., 2011. Fault lubrication during earthquakes, Nature, 471(7339), 494-498.

Economides, M.J., 2000. Reservoir Stimulation, 3rd edn, John Wiley \& Sons.

Ellsworth, W.L., 2013. Injection-induced earthquakes, Science, 341(6142), 1225942-1225942.

Eppelbaum, L., Kutasov, I. \& Pilchin, A., 2014. Applied Geothermics. Endeavour, Vol. 11, Springer. 
Evans, D.M., 1966. The Denver area earthquakes and the Rocky Mountain Arsenal disposal well, Mt. Geologist, 3, 23-36.

Fan, Z., Eichhubl, P. \& Gale, J.F.W., 2016. Geomechanical analysis of fluid injection and seismic fault slip for the $M_{\mathrm{w}} 4.8$ Timpson, Texas, earthquake sequence, J. geophys. Res., 121(4), 2798-2812.

Frohlich, C., Ellsworth, W., Brown, W.A., Brunt, M., Luetgert, J., MacDonald, T. \& Walter, S., 2014. The 17 May 2012 M 4.8 earthquake near Timpson, East Texas: an event possibly triggered by fluid injection, $J$. geophys. Res., 119(1), 581-593.

Giordano, D., Russell, J.K. \& Dingwell, D.B., 2008. Viscosity of magmatic liquids: a model, Earth planet. Sci. Lett., 271(1-4), 123-134.

Goertz-Allmann, B.P., Goertz, A. \& Wiemer, S., 2011. Stress drop variations of induced earthquakes at the Basel geothermal site, Geophys. Res. Lett., 38(9), doi:10.1029/2011GL047498.

Grandin, R., Vallée, M. \& Lacassin, R., 2017. Rupture process of the $M_{\mathrm{w}} 5.8$ Pawnee, Oklahoma, earthquake from Sentinel-1 InSAR and seismological data, Seismol. Res. Lett., 88(4), 994-1004.

Green, C., Styles, P. \& Baptie, B., 2012, Induced Seismicity Mitigation Report. Retrieved from https://assets.publishing.service.gov.uk/governm ent/uploads/system/uploads/attachment_data/file/48330/5055-preese-ha 11-shale-gas-fracturing-review-and-recomm.pdf.

Green, H.W., II, Shi, F., Bozhilov, K., Xia, G. \& Reches, Z., 2015. Phase transformation and nanometric flow cause extreme weakening during fault slip, Nat. Geosci., 8(6), 484-489.

Grigoli, F. et al., 2017. Current challenges in monitoring, discrimination, and management of induced seismicity related to underground industrial activities: a European perspective, Rev. Geophys., 55(2), 310-340.

Han, R., Shimamoto, T., Hirose, T., Ree, J.-H. \& Ando, J.-I., 2007. Ultralow friction of carbonate faults caused by thermal decomposition, Science, 316(5826), 878-881.

Häring, M.O., Schanz, U., Ladner, F. \& Dyer, B.C., 2008. Characterisation of the Basel 1 enhanced geothermal system, Geothermics, 37(5), 469-495.

Healy, J.H., Rubey, W.W., Griggs, D.T. \& Raleigh, C.B., 1968. The Denver earthquakes. Disposal of waste fluids by injection into a deep well has triggered earthquakes near Denver, Colorado, Science, 161, 1301-1310.

Heaton, T.H., 1990. Evidence for and implications of self-healing pulses of slip in earthquake rupture, Phys. Earth planet. Inter., 64(1), 1-20.

Holditch, S.A., Ely, J.W., Semmelbeck, M.E., Carter, R.H., Hinkel, J. \& Jeffrey, R.G., Jr., 1988. Enhanced recovery of coalbed methane through hydraulic fracturing, in SPE Annual Technical Conference and Exhibition, Houston, Texas, Society of Petroleum Engineers, doi:10.2118/18250-MS

Hsieh, P.A. \& Bredehoeft, J.D., 1981. A reservoir analysis of the Denver earthquakes: a case of induced seismicity, J. geophys. Res., 86(B2), 903920.

Huang, Y., Ellsworth, W.L. \& Beroza, G.C., 2017. Stress drops of induced and tectonic earthquakes in the central United States are indistinguishable, Sci. Adv., 3(8), e1700772, doi:10.1126/sciadv.1700772.

Keranen, K.M., Savage, H.M., Abers, G.A. \& Cochran, E.S., 2013. Potentially induced earthquakes in Oklahoma, USA: links between wastewater injection and the $2011 M_{\mathrm{w}} 5.7$ earthquake sequence, Geology, 41(6), 699-702.

Kim, W.-Y., 2013. Induced seismicity associated with fluid injection into a deep well in Youngstown, Ohio, J. geophys. Res., 118(7), 3506-3518.

King, V.M., Block, L.V, Yeck, W.L., Wood, C.K. \& Derouin, S.A., 2014. Geological structure of the Paradox Valley Region, Colorado, and relationship to seismicity induced by deep well injection, J. geophys. Res., 119(6), 4955-4978.

King Hubbert, M. \& Rubey, W.W., 1959. Role of fluid pressure in mechanics of overthrust faulting, Bull. geol. Soc. Am., 70(2), 115-166.

McGarr, A. et al., 2014. Coping with earthquakes induced by fluid injection, J. geophys. Res., 1-12, doi:10.1002/2013JB010597, Received.

McNamara, D.E., Benz, H.M., Herrmann, R.B., Bergman, E.A., Earle, P., Holland, A., Baldwin, R.W. \& Gassner, A., 2015. Earthquake hypocenters and focal mechanisms in central Oklahoma reveal a complex system of reactivated subsurface strike-slip faulting, Geophys. Res. Lett., 42(8), 2742-2749.

Morris, A.P., Ferrill, D.A., Walter, G.R., Price, A.M., Smart, K.J., Skoumal, R.J., Brudzinski, M.R. \& Currie, B.S., 2017. Lessons learned from the
Youngstown, Ohio induced earthquake sequence from January 2011 to January 2012, J. Rock Mech. Geotech. Eng., 9(5), 783-796.

Noël, C., Passelègue, F.X., Giorgetti, C. \& Violay, M., 2019. Fault reactivation during fluid pressure oscillations: transition from stable to unstable slip, J. geophys. Res., 2019JB018517, doi:10.1029/2019JB018517.

Novotny, E.J., 1977. Proppant Transport, in SPE Annual Fall Technical Conference and Exhibition, Society of Petroleum Engineers, Denver, Colorado, doi:10.2118/6813-MS.

ODNR, 2012. Preliminary Report on the North Star 1 Class II Injection Well and the Seismic Events in the Youngstown, Ohio, Area. Ohio Department of Natural Resources.

Otsuki, K., Monzawa, N. \& Nagase, T., 2003. Fluidization and melting of fault gouge during seismic slip: identification in the Nojima fault zone and implications for focal earthquake mechanisms, J. geophys. Res., 108(B4), doi:10.1029/2001jb001711.

Pollitz, F.F., Wicks, C., Ellsworth, W., Murray, M. \& Schoenball, M., 2017. Geodetic slip model of the 3 September $2016 M_{\mathrm{w}} 5.8$ Pawnee, Oklahoma, Earthquake: evidence for fault-zone collapse, Seismol. Res. Lett., 88, 953-955,

Raleigh, A.C.B., Healy, J.H. \& Bredehoeft, J.D., 1976. An experiment in earthquake control at Rangely, Colorado, Science, 191(4233), 1230-1237.

Reches, Z. \& Lockner, D.A., 2010. Fault weakening and earthquake instability by powder lubrication, Nature, 467(7314), 452-455.

Rempel, A.W. \& Rice, J.R., 2006. Thermal pressurization and onset of melting in fault zones, J. geophys. Res., 111(9), doi:10.1029/2006JB004314.

Rice, J.R., 2006. Heating and weakening of faults during earthquake slip, $J$. geophys. Res., 111(B5), doi:10.1029/2005JB004006.

Rowe, C.D. \& Griffith, W.A., 2015. Do faults preserve a record of seismic slip: A second opinion, J. Struct. Geol., 78, 1-26.

Schultz, R., Wang, R., Gu, Y.J., Haug, K. \& Atkinson, G., 2017. A seismological overview of the induced earthquakes in the Duvernay play near Fox Creek, Alberta, J. geophys. Res., 122(1), 492-505.

Shen, L., , Schmitt, D.R. \& Haug, K., 2018, Measurements of the States of In Situ Stress for the Duvernay Formation near Fox Creek, West-Central Alberta, Alberta Energy Regulator/Alberta Geological Survey, AER/AGS Report 97. , .

Sibson, R.H., 1986. Brecciation processes in fault zones: inferences from earthquake rupturing, Pure appl. Geophys., 124(1-2), 159-175.

Suckale, J., 2009. Induced Seismicity in Hydrocarbon Fields, Adv. Geophys., 51(C), 55-106.

Sun, X. \& Hartzell, S., 2014. Finite-fault slip model of the $2011 \mathrm{M}_{\mathrm{w}} 5.6$ Prague, Oklahoma earthquake from regional waveforms, Geophys. Res. Lett., 41(12), 4207-4213.

Thiercelin, M.J. \& Plumb, R.A., 1994. A core-based prediction of lithologic stress contrasts in East Texas Formations, SPE Formation Eval., 9(4), 251-258.

Valley, B. \& Evans, K.F., 2019. Stress magnitudes in the Basel enhanced geothermal system, International Journal of Rock Mechanics and Mining Sciences, 118, 1-20,

Violay, M., Di Toro, G., Nielsen, S., Spagnuolo, E. \& Burg, J.P., 2015. Thermo-mechanical pressurization of experimental faults in cohesive rocks during seismic slip, Earth planet. Sci. Lett., 429, 1-10.

Walsh, F.R. \& Zoback, M.D., 2016. Probabilistic assessment of potential fault slip related to injection-induced earthquakes: application to northcentral Oklahoma, USA, Geology, 44(12), 991-994.

Wang, R., Gu, Y.J., Schultz, R., Kim, A. \& Atkinson, G., 2016. Source analysis of a potential hydraulic-fracturing-induced earthquake near Fox Creek, Alberta, Geophys. Res. Lett., 43(2), 564-573.

Weingarten, M., Ge, S., Godt, J.W., Bekins, B.A. \& Rubinstein, J.L., 2015. High-rate injection is associated with the increase in U.S. mid-continent seismicity, Science, 348(6241), 1336-1340.

Yeck, W.L., Block, L.V., Wood, C.K. \& King, V.M., 2015. Maximum magnitude estimations of induced earthquakes at Paradox Valley, Colorado, from cumulative injection volume and geometry of seismicity clusters, Geophys. J. Int., 200(1), 322-336.

Zoback, M.D., 2007. Rock failure in compression, tension and shear, in Reservoir Geomechanics, pp. 84-139, Cambridge Univ. Press, doi:10.1017/CBO9780511586477.005. 
Zoback, M.D. \& Kohli, A.H., 2019. Geomechanics and Stimulation Optimization, in Unconventional Reservoir Geomechanics: Shale Gas, Tight Oil, and Induced Seismicity, pp. 322-344, Cambridge Univ. Press, doi:10.1017/9781316091869.012.
Eisner, Leo, Gei, Davide, Hallo, Miroslav, Opršal, Ivo \& Ali, Mohammed Y., 2013. The peak frequency of direct waves for microseismic events, GEOPHYSICS, 78(8):A45-A49. 